\title{
Determinants of Anemia Among Pregnant Women Attending in a Tertiary Level Hospital, Kathmandu
}

\author{
Mulepati Sumitra ${ }^{1}$, Chaudhary Tanuja Kumari* ${ }^{2}$ \\ ${ }^{1}$ Army Institute of Health Science, Kathmandu \\ ${ }^{2}$ Birgunj Nursing Campuses, IOM, TU
}

\section{ABSTRACT}

Background: Anemia is a common problem in pregnancy, particularly in developing countries which causes low birth weight and increased risk of maternal and perinatal morbidity and mortality.

Methods: A descriptive cross-sectional study was adopted to determine the factors associated with anemia among pregnant Systematic Random Sampling technique was used and sample size was 280 pregnant women who visited the antenatal clinic of the Tribhuwan University Teaching Hospital, Kathmandu. Data was collected by face to face interview technique by pretested questionnaire. Chi-square, bivariate, multivariate logistic regression model was used, and statistical significance was determined with a 95\% confidence level.

Results: Mean age of respondents was $25.86 \pm 4.191$ years. Anemia among pregnant women was $22.1 \%$. The significant determinants associated with anemia were pregnant women who had not taken iron regularly $(\mathrm{AOR}=18.380,95 \% \mathrm{CI}=3.687-91.624, p=0.005)$.

Conclusion: The results indicate that anemia is still prevalence in pregnant women in tertiary level hospital at Kathmandu. Irregular intake or discontinuation of iron was significant factor for anemia. Therefore, pregnant women and their family members need counseling about the importance of regular intake of iron during pregnancy.
Keywords: Anemia, Antenatal clinic , Determinants, Hemoglobin, Pregnant women

*Corresponding Author- Tanuja Kumari Chaudhary, Birgunj Nursing Campus, IOM, TU Email: tanujachaudhary2017@gmail.com

\section{INTRODUCTION}

Pregnancy is a period of a significant increase in iron requirement over and above the nonpregnant state. Although iron requirements are reduced in the first trimester because of the absence of menstruation, they rise steadily thereafter from approximately $0.8 \mathrm{mg}$ per day in the first month to approximately $10 \mathrm{mg}$ per day during the last 6 weeks of pregnancy. The increased iron requirement is due to expansion of maternal red blood cell mass for increased oxygen transport, including transfer of iron, to both the growing foetus and the placental structures, and as a needed reserve for blood loss and lochia at parturition. Due to increased iron requirements, pregnancy is also a period of increased risk for anaemia. Thus, a high proportion of women become anaemic during pregnancy. ${ }^{1,2,3}$ It is the commonest hematological disorder accompanying pregnancy. ${ }^{4,5}$

Globally, $41.8 \%$ pregnant women and close to one third of non-pregnant women (30.2\%) are anaemic. Anaemia during pregnancy contributes to $20 \%$ of all maternal deaths and it increases the risks of foetal, neonatal and overall infant mortality. ${ }^{2}$ Anemia is 
defined as a low blood hemoglobin concentration below $11 \mathrm{~g} / \mathrm{dl}$. It has been shown to be a global public health problem that affects low, middle and highincome countries and has significant adverse health consequences, as well as adverse impacts on social and economic development. ${ }^{6}$ Anemia during pregnancy is considered severe when $\mathrm{Hb}$ concentration is less than $7.0 \mathrm{~g} / \mathrm{dl}$, moderate when $\mathrm{Hb}$ level is $7.0-9.9 \mathrm{~g} / \mathrm{dl}$, and mild when $\mathrm{Hb}$ level is $10.0-10.9 \mathrm{~g} / \mathrm{dl}{ }^{3,7}$ Anemia during pregnancy is a major cause of morbidity and mortality of pregnant women in developing countries and has both maternal and fetal consequences. ${ }^{7}$ It is estimated that anemia causes more than 115,000 maternal and 591,000 perinatal deaths globally per year. ${ }^{4}$

Anaemia during pregnancy is of great concern because it contributes significantly to increased risk of maternal death during the prenatal period. Anaemia increases the risk of postpartum haemorrhage, pregnancy-induced hypertension, placenta praevia, haemorrhage and cardiac failure. Overall, $20-40 \%$ of the estimated 50000 maternal deaths worldwide associated with child birth or the postpartum period are attributed to anaemia during pregnancy. Anaemia is also an established risk factor for intrauterine growth retardation and subsequent low birth weight, preterm delivery, prenatal death. ${ }^{5,6,8}$

In developing countries, the cause of anaemia during pregnancy is multifactorial and includes nutritional deficiencies of iron, folate, and vitamin B12 and also parasitic diseases, such as malaria and hookworm. Iron deficiency is the cause of $75 \%$ of anaemia cases during pregnancy ${ }^{4}$. Iron deficiency anaemia affects the development of the nation by decreasing the cognitive and motor development of children and productivity of adults. ${ }^{5,7}$ The prevalence of iron deficiency was 10 times higher than that of folate deficiency or vitamin B-12 deficiency. The major factor responsible for nutritional anemia is a deficiency of iron, with folate. ${ }^{9}$

According to Nepal Demographic Health Survey 2016 shows that forty-one percent of women age 15-49 are anemic. The majority of these women are mildly anemic (34\%); $7 \%$ are moderately anemic, and less than $1 \%$ are severely anemic.
Pregnant women and breastfeeding women (each $46 \%$ ) are more likely to be anemic than other women (39\%). Anemia levels vary by states; for example, $58 \%$ of women residing in State 2 are anemic compared with only $28 \%$ in State 4 . There is no clear pattern on prevalence of anemia by wealth. The prevalence of anemia among women has increased in the past 5 years from $35 \%$ in 2011 to $41 \%$ in 2016 . However, the prevalence of anemia among pregnant women has declined slightly from $48 \%$ in 2011 to $46 \%$ in 2016. Overall, $42 \%$ of women took the recommended dose of iron tablets for at least 180 days during their last pregnancy. ${ }^{10}$

Currently, Ministry of Health and Population (MOHP) in Nepal has a policy to treat anemic pregnant women with iron supplements. In addition, Female Community Health Volunteers (FCHVs) are to distribute iron and deworming tablets to all pregnant women. Yet, anemia prevalence in Nepal is unacceptably high. This could be due to the presence of other factors that limit the woman's response to iron supplementation. Maternal anemia programs are most effective when they address the multiple causes of anemia through integrated interventions. ${ }^{11}$

In spite of intervention effort as in developing countries like Nepal, high level of anemia among pregnant women continue.Though Nepal has decreasing trend of prevalence of anemia, it is still high (46\% in 2016). Identifying the associated factors which are responsible for the development of anemia during pregnancy would be of great help in mitigating the burden to some extent. Therefore, the purpose of this study is to find out the various determinants of anemia among the pregnant women

\section{MATERIALS AND METHODS}

Descriptive cross-sectional research design was adopted for the study to findout the various determinants of anemia among the pregnant women attending antenatal clinic in a tertiary level hospital, Kathmandu. Respondents selected by systematic random sampling technique. Sampling frame was drawn from register of antenatal clinic. The sample size was 280. Pregnant women were from second 
or third trimester, attend antenatal clinic of TUTH with hemoglobin report done in this pregnancy and who are willing to participate in the study were included in this study similarly those pregnant women who have diagnose as pathological diseases were excluded from study. Data was collected by interview method from 28 February to 27 March, 2016. Ethical approval was obtained from Institutional Review Board of TU, IOM. However, an authorization taken from TUTH to collect data. Verbal consent was obtained from each respondent. Confidentiality was maintained by giving code number and conducting the interview separately. Every interview takes 20-25 min. After finishing the interview, information was provided to make aware about preventive measure of anemia. Data entry was done in excel and analysis of questionnaires was done in Statistical Package of Social Sciences (SPSS) 16 based on the coded questionnaires. Chisquare, bivariate, and multivariate (binary logistic regression) analysis was used with statistical standard 95\% confidence interval (CI). Unadjusted and Adjusted odds ratio were calculated to measure the net effect of variables on anemia.

\section{RESULTS}

Table 1a : Association of Socio Demographic Characteristics: Age, Ethnicity, Religion, Literacy Status of Pregnant Women and Anemia

\begin{tabular}{|c|c|c|c|c|}
\hline \multirow[t]{2}{*}{ Socio-Demographic Characteristics } & \multicolumn{2}{|l|}{ Anemia } & \multirow[t]{2}{*}{$p$-Value } & \multirow[t]{2}{*}{ Unadjusted OR $(95 \% \mathrm{CI})$} \\
\hline & $\begin{array}{l}\text { Yes }(n=62) \\
22.1 \%\end{array}$ & $\begin{array}{l}\text { No }(n=218) \\
77.9 \%\end{array}$ & & \\
\hline $\begin{array}{l}\text { Age } \\
\leq 25 \text { years } \\
>25 \text { years }\end{array}$ & $\begin{array}{l}33(22.8) \\
29(21.5)\end{array}$ & $\begin{array}{l}112(77.2) \\
106(78.5) \\
\end{array}$ & 0.797 & $\begin{array}{l}1.077(0.612-1.895) \\
1\end{array}$ \\
\hline \multicolumn{5}{|l|}{ Ethnicity } \\
\hline Brahmin/Chhetri & $35(22.2)$ & $123(77.8)$ & 0.997 & $1.001(0.567-1.769)$ \\
\hline Others & $27(22.1)$ & $95(77.9)$ & & 1 \\
\hline \multicolumn{5}{|l|}{ Religion } \\
\hline Hindu & $52(21.9)$ & $185(78.1)$ & 0.848 & $0.928(0.429-2.0060$ \\
\hline Others & $10(23.3)$ & $33(76.7)$ & & 1 \\
\hline \multicolumn{5}{|l|}{ Literacy status } \\
\hline Illiterate & $2(18.2)$ & $9(81.8)$ & 1.000 & $0.774(0.163-3.679)$ \\
\hline Literate & $60(22.3)$ & $209(77.7)$ & & 1 \\
\hline
\end{tabular}

*Fisher's exact test **p value Significant $<0.051$ Reference

Table 1a reveals that association of socio demographic characteristics: Age, Ethnicity, Religion, Literacy status of pregnant women and Anemia. There were no significant association between age, ethnicity, religion, literacy status and anemia.

Table 1b : Association of Socio-Demographic Characteristics: Occupation, Household Income, Family members and Type of Family of Pregnant Women with Anemia

\begin{tabular}{|c|c|c|c|c|}
\hline \multirow{2}{*}{ Socio-Demographic Characteeristics } & \multicolumn{2}{|l|}{ Anemia } & \multirow{2}{*}{$P$-Value } & \multirow{2}{*}{ Unadjusted OR (95\% CI) } \\
\hline & $\begin{array}{l}\text { Yes }(\mathrm{n}=62) \\
22.1 \%\end{array}$ & $\begin{array}{l}\text { No }(\mathrm{n}=218) \\
77.9 \%\end{array}$ & & \\
\hline $\begin{array}{l}\text { Occupation } \\
\text { Dependent women } \\
\text { Independent women } \\
\text { Household Income }\end{array}$ & $\begin{array}{l}46(23.10) \\
16(19.8)\end{array}$ & $\begin{array}{l}153(76.9) \\
65(80.2)\end{array}$ & 0.539 & $\begin{array}{l}1.221(0.645-2.313) \\
1\end{array}$ \\
\hline Income not enough for 1 year & $28(27.2)$ & $75(72.8)$ & 0.121 & $1.570(0.885-2.785)$ \\
\hline Income enough for 1 year and surplus & $34(19.2)$ & $143(80.8)$ & & 1 \\
\hline \multicolumn{5}{|l|}{ Family Members } \\
\hline$>5$ member & $24(30.0)$ & $55(69.6)$ & $0.037 * *$ & $1.872(1.032-3.395)$ \\
\hline$\leq 5$ members & $38(18.9)$ & $163(81.1)$ & & 1 \\
\hline \multicolumn{5}{|l|}{ Types of Family } \\
\hline Nuclear & $21(18.6)$ & $92(81.4)$ & 0.238 & $0.701(0.389-1.266)$ \\
\hline Joint Family & $41(24.6)$ & $126(75.4)$ & & 1 \\
\hline
\end{tabular}

*Fisher's exact test $* *$ p value Significant $<0.051$ Reference 
Table 1b shows that Family members were significantly associated with anemia in pregnancy $(p=0.037)$. Those pregnant women who came from more than 5 family members were 1.87 times more likely to occur anemia than women who came from less than 5 or in 5 family members $(\mathrm{OR}=1.872$, 95\% CI=1.032-3.395). Other variables like occupation, household income, type of family were not associated with Anemia.

Table 2 : Association of Knowledge of Pregnant Women with Anemia

\begin{tabular}{|c|c|c|c|c|}
\hline \multirow[b]{2}{*}{ Characteristics } & \multicolumn{2}{|c|}{ Anemia } & \multirow[b]{2}{*}{$p$-value } & \multirow{2}{*}{$\begin{array}{l}\text { Unadjusted Odds Ratio } \\
\qquad(95 \% \text { CI })\end{array}$} \\
\hline & $\begin{array}{c}\text { Yes }(n=62) \\
22.1 \%\end{array}$ & $\begin{array}{c}\text { No }(n=218) \\
77.9 \%\end{array}$ & & \\
\hline \multicolumn{5}{|c|}{ Heard about Anemia $(\mathrm{n}=280)$} \\
\hline Yes & $58(21.6 \%)$ & $211(78.4 \%)$ & 0.246 & $0.481(0.136-1.700)$ \\
\hline No & $4(36.4 \%)$ & $7(63.6 \%)$ & & 1 \\
\hline \multicolumn{5}{|c|}{ Level of Knowledge about Anemia } \\
\hline Inadequate & $37(25.7 \%)$ & $107(74.4 \%)$ & 0.141 & $1.535(0.866-2.722)$ \\
\hline Adequate & $25(18.4 \%)$ & $111(81.6 \%)$ & & 1 \\
\hline
\end{tabular}

**p value Significant $<0.051$ Reference

Table 2 shows that the pregnant women who have not adequate knowledge about anemia were 1.535 times more likely to develop anemia than who have adequate knowledge about anemia ( $\mathrm{UOR}=1.535$, CI:0.866-2.722, $\mathrm{p}=0.141$ )

Table 3 : Association of Obstetric related Characteristics of Pregnant Women: Trimester, Gravida, Times of Pregnancy,History ofAbortion, Inter pregnancy difference, History of Heavy Menstruation, History of Use of Temporary Contraceptives and Anemia

$\mathbf{n}=\mathbf{2 8 0}$

\begin{tabular}{|c|c|c|c|c|}
\hline \multirow{2}{*}{ Obstetric Characteristics } & \multicolumn{2}{|c|}{ Anemia } & \multirow[t]{2}{*}{$p$-value } & \multirow{2}{*}{$\begin{array}{l}\text { Unadjusted Odds Ratio } \\
(95 \% \mathrm{CI})\end{array}$} \\
\hline & $\begin{array}{c}\text { Yes }(n=62) \\
22.1 \%\end{array}$ & $\begin{array}{c}\text { No }(n=218) \\
77.9 \%\end{array}$ & & \\
\hline \multicolumn{5}{|l|}{ Trimester } \\
\hline Second Trimester & $14(17.7)$ & $65(82.3)$ & 0.264 & $0.687(0.354-1.331)$ \\
\hline Third Trimester & $48(23.9)$ & $153(76.1)$ & & 1 \\
\hline \multicolumn{5}{|l|}{ Gravida } \\
\hline Primigravida & $20(17.7)$ & $93(82.3)$ & 0.141 & $0.640(0.353-1.162)$ \\
\hline Multi gravida & $42(25.1)$ & $125(74.9)$ & & 1 \\
\hline \multicolumn{5}{|l|}{ Times of Pregnancy } \\
\hline Multigravida $\leq 3$ & $38(24.5)$ & $117(75.5)$ & 0.498 & $0.650(0.185-2.278)$ \\
\hline Multi gravida $>3$ & $4(33.3)$ & $8(66.7)$ & & 1 \\
\hline \multicolumn{5}{|l|}{ History of Abortion } \\
\hline Yes & $23(28.8)$ & $57(71.2)$ & 0.092 & $1.666(0.917-3.027)$ \\
\hline No & $39(19.5)$ & $161(80.5)$ & & 1 \\
\hline \multicolumn{5}{|l|}{ Inter Pregnancy Difference } \\
\hline$<2$ years & $24(36.9)$ & $41(63.1)$ & $0.005 * *$ & $2.732(1.335-5.591)$ \\
\hline$>2$ years & $18(17.6)$ & $84(82.4)$ & & 1 \\
\hline \multicolumn{5}{|c|}{ History of Heavy Menstruation } \\
\hline Yes & $15(32.6)$ & $31(67.4)$ & 0.061 & $1.925(0.961-3.855)$ \\
\hline No & $47(20.1)$ & $187(79.9)$ & & 1 \\
\hline \multicolumn{3}{|c|}{ History of Use of Temporary Contraceptives } & & \\
\hline Yes & $12(23.5)$ & $39(76.5)$ & 0.792 & $1.102(0.537-2.261)$ \\
\hline No & $50(21.8)$ & $179(78.20$ & & 1 \\
\hline
\end{tabular}

**p value Significant $<0.051$ Reference

Table 3 shows that inter pregnancy difference were significantly associated with anemia $(p=0.005)$. The pregnant women who had less than 2 years inter pregnancy difference was 2.7 times more likely to anemia $(\mathrm{OR}=2.732,95 \% \mathrm{CI}=1.335-5.591)$ than those who had more than 2 years inter pregnancy difference. Similarly, trimester, times of pregnancy, history of abortion, history of heavy menstruation, history of use of temporary contraceptives were not significantly associated with anemia in pregnancy. 
Table 4: Association of Health Service related Characteristics of Pregnant Women: ANC Visit, Iron Started from, Duration of Iron, Regularity of Iron, Use of Deworming and Anemia

$\mathbf{n}=\mathbf{2 8 0}$

\begin{tabular}{|l|c|c|c|c|}
\hline Characteristics & \multicolumn{2}{|c|}{ Anemia } & $p$-value & Unadjusted Odds Ratio (95\% CI) \\
\hline & $\begin{array}{c}\text { Yes(n=62) } \\
\mathbf{2 2 . 1} \%\end{array}$ & $\begin{array}{c}\text { No(n=218) } \\
\mathbf{7 7 . 9 \%}\end{array}$ & & \\
\hline $\begin{array}{c}\text { ANC Visit } \\
\leq 2 \text { Times }\end{array}$ & $13(50.0)$ & $13(50.0)$ & $0.000 * *$ & $4.184(1.825-9.590)$ \\
\hline$>2$ Times & $49(19.3)$ & $205(80.7)$ & & 1 \\
\hline Iron started from & & & & $16.000(3.302-77.518)$ \\
\hline From 3 rd trimester & $8(80.0)$ & $2(20.0)$ & $0.000^{* *}$ & 1 \\
\hline From 2 ${ }^{\text {nd }}$ trimester & $54(20.0)$ & $216(80.0)$ & & $5.727(3.039-10.794)$ \\
\hline Duration of Iron & & & & 1 \\
\hline$\leq 2$ month & $29(50.0)$ & $29(50.0)$ & $0.000 * *$ & $36.707(10.465-128.761)$ \\
\hline$>2$ month & $33(14.9)$ & $189(85.1)$ & & 1 \\
\hline Regularity of Iron & & & & \\
\hline No & $21(87.5)$ & $3(12.5)$ & $0.000 * *$ & $0.741(0.206-2.665)$ \\
\hline Yes & $41(16.0)$ & $215(84.0)$ & & 1 \\
\hline Use of Deworming & & & & \\
\hline Yes & $3(17.6)$ & $14(82.4)$ & $0.772 *$ & \\
\hline No & $59(22.4)$ & $204(77.6)$ & & \\
\hline
\end{tabular}

*Fisher exact test, ${ }^{* *}$ p value Significant $<0.05,1$ Reference

Table 4 shows that ANC visit is statistically significant with anemia in pregnancy $(p=0.000)$. Pregnant women who attend ANC visit in less or equal to 2 times were 4.18 times more likely to develop anemia than those pregnant women who attained more than $2 \mathrm{ANC}$ visit $(\mathrm{OR}=4.184,95 \% \mathrm{CI}=1.825-9.590)$. The pregnant women who started iron from 3rd trimester 16.0 times more likely to develop anemia than pregnant women who started iron from second trimester and statistically significant $(\mathrm{OR}=16.000$, $95 \%$ CI 3.302-77.518, $\mathrm{p}=0.000)$. Regularity of iron was significant with anemia among pregnancy $(\mathrm{p}=0.000)$. The pregnant women who had not taken regular iron were 36.7 times more likely to occur anemia than women who took regular iron $(\mathrm{OR}=36.707,95 \% \mathrm{CI}=10.465-128.761)$.

Table 5 a :Association of Dietary Habit: Dietary Status, Meat per week, Green Vegetables per week, Fruits per week of Pregnant Women and Anemia

\begin{tabular}{|c|c|c|c|c|}
\hline \multirow[t]{3}{*}{ Variables } & \multicolumn{2}{|c|}{ Anemia No Anemia } & \multirow[t]{3}{*}{$p$-value } & \multirow[t]{3}{*}{ Unadjusted OR $(95 \% \mathrm{CI})$} \\
\hline & $\operatorname{Yes}(n=62)$ & $\operatorname{No}(n=218)$ & & \\
\hline & $22.1 \%$ & $77.9 \%$ & & \\
\hline \multicolumn{5}{|c|}{ Dietary Status(n=280) } \\
\hline Vegetarian & 9(33.3), & $18(66.7)$ & 0.141 & $1.887(0.802-4.439)$ \\
\hline Non vegetarian & $53(20.9)$ & $200(79.1)$ & & 1 \\
\hline \multicolumn{5}{|c|}{ Meat per week $(n=253)$} \\
\hline$\leq 1$ per week & $32(27.4)$ & $85(72.6)$ & $0.020 * *$ & $2.062(1.112-3.824)$ \\
\hline$>1$ per week & $21(15.4)$ & $115(84.6)$ & & 1 \\
\hline \multicolumn{5}{|c|}{$\begin{array}{llll}\begin{array}{l}\text { Green } \\
(n=280)\end{array} & \text { vegetable per week } \\
\end{array}$} \\
\hline$\leq 2$ times a week & $12(28.6)$ & $30(71.4)$ & 0.276 & $1.504(0.719-3.148)$ \\
\hline$>2$ times a week & $50(21.0)$ & $188(79.0)$ & & 1 \\
\hline \multicolumn{5}{|c|}{ Fruits per week $(n=253)$} \\
\hline$\leq 2$ times a week & $29(41.4)$ & $41(58.6)$ & $0.000 * *$ & $3.794(2.075-6.937)$ \\
\hline$>3$ times a week & $33(15.7)$ & $177(84.7)$ & & 1 \\
\hline
\end{tabular}

$* *$ p value significant $<0.05,1$ Reference

Table 5a revealed that dietary habit of meat per week was significantly associated with anemia $(p=0.020)$. Those pregnant women who had consume meat one or less than 1 times in a week was 2 times more likely to develop anemia than pregnant pregnant women who had consume meat more than 1 times consumed in a week $(\mathrm{OR}=2.062,95 \% \mathrm{CI}=1.112-3.824)$. The odds of having anemia in pregnant women who had taken fruits less than or equal to 2 times a week were 3.79 times more likely to occur anemia $(\mathrm{OR}=3.794,95 \% \mathrm{CI}=2.075-6.937 \mathrm{p}=0.000)$. There is significantly association between fruits consumption and anemia. 
Table 5 b: Association of Dietary Habits: Meal per Day, Food Taboos, Drinking Tea, Tea immediately after Meal or With Meal of Pregnant Women and Anemia

$\mathbf{n}=\mathbf{2 8 0}$

\begin{tabular}{|c|c|c|c|c|}
\hline \multirow[t]{2}{*}{\begin{tabular}{|l|} 
Variables \\
\end{tabular}} & \multicolumn{2}{|c|}{ Anemia } & \multirow[t]{2}{*}{$p$-value } & \multirow[t]{2}{*}{ Unadjusted OR $(95 \% \mathrm{CI})$} \\
\hline & $\begin{array}{c}\text { Yes }(n=62) \\
22.1 \%\end{array}$ & $\begin{array}{c}\text { No }(n=218) \\
77.9 \%\end{array}$ & & \\
\hline $\begin{array}{c}\text { Meal per Day } \\
\quad \leq 3 \text { times a day } \\
>3 \text { times a day } \\
\end{array}$ & $\begin{array}{l}36(25.5) \\
26(18.7)\end{array}$ & $\begin{array}{l}105(74.50 \\
113(81.3) \\
\end{array}$ & 0.169 & $\begin{array}{c}1.490(0.843-2.635) \\
1\end{array}$ \\
\hline \multicolumn{5}{|l|}{\begin{tabular}{|l|} 
Food Taboos \\
\end{tabular}} \\
\hline Yes & $13(26.0)$ & $37(74.0)$ & 0.458 & $1.298(0.640-2.630)$ \\
\hline No & $49(21.3)$ & $181(78.7)$ & & 1 \\
\hline \multicolumn{5}{|l|}{ Drinking Tea } \\
\hline Yes & $59(26.5)$ & $164(73.5)$ & $0.001 * *$ & $6.476(1.950-21.501)$ \\
\hline No & $3(5.3)$ & $54(94.70$ & & 1 \\
\hline \multicolumn{5}{|c|}{ Tea immediately after meal or with meal } \\
\hline Yes & $57(31.0)$ & $127(69.0)$ & $0.001 * *$ & $8.303(1.935-35.638)$ \\
\hline No & $2(5.1)$ & $37(94.9)$ & & 1 \\
\hline
\end{tabular}

**p value Significant $<0.051$ Reference

Table $5 \mathrm{~b}$ shows that the pregnant women who had habit of drinking tea were 6.47 times more likely to occur anemia than those who did not taken tea $(\mathrm{OR}=6.476,95 \% \mathrm{CI}=1.950-21.501, \mathrm{p}=0.001)$. So there is significantly association between tea consumption and anemia. The pregnant women who had habit of drinking tea immediately after meal or with meal was 8.3 times more likely to occur anemia than those who had no habit of drinking tea immediately after meal $(\mathrm{OR}=8.303,95 \% \mathrm{CI}=1.935-35.638$, $\mathrm{p}=0.001)$. So there is association between Tea consumption with meal or after meal and anemia.

Table 6 : Determinants of Anemia among pregnant women

\begin{tabular}{|c|c|c|c|c|}
\hline Variables & UOR $(95 \% \mathrm{CI})$ & $p$-value & $\operatorname{AOR}(95 \% \mathrm{CI})$ & $p$-value \\
\hline \multicolumn{5}{|l|}{ Iron regularly } \\
\hline No & $36.707(10.465-128.761)$ & 0.000 & $18.380(3.687-91.624)$ & $0.005 * *$ \\
\hline Yes & 1 & & 1 & \\
\hline \multicolumn{5}{|l|}{ Family member } \\
\hline$>5$ Members & $1.872(1.032-3.395)$ & 0.037 & $1.123(0.382-3.300)$ & 0.833 \\
\hline$\leq 5$ Members & 1 & & 1 & \\
\hline \multicolumn{5}{|l|}{ Fruit per week } \\
\hline$\leq 2$ per week & $3.794(2.075-6.937)$ & 0.000 & $1.156(0.389-3.431)$ & 0.795 \\
\hline$>\mathbf{2 p e r}$ week & 1 & & 1 & \\
\hline \multicolumn{5}{|l|}{ Meat per week } \\
\hline$<1$ & $2.062(1.112-3.824)$ & 0.020 & $1.219(0.449-3.309)$ & 0.697 \\
\hline$>1$ & 1 & & 1 & \\
\hline \multicolumn{5}{|l|}{ ANC visits } \\
\hline$\leq 2$ times & $4.184(1.825-9.590)$ & 0.000 & $2.538(0.496-12.993)$ & 0.264 \\
\hline$>2$ times & 1 & & 1 & \\
\hline \multicolumn{5}{|l|}{ Drinking Tea } \\
\hline Yes & $6.476(1.950-21.501)$ & 0.001 & $2.822(0.573-13.906)$ & 0.202 \\
\hline No & 1 & & 1 & \\
\hline \multicolumn{5}{|c|}{ Inter pregnancy difference } \\
\hline$<2 \mathrm{yr}$ & $2.732(1.335-5.591)$ & 0.005 & $1.736(0.637-4.734)$ & 0.281 \\
\hline$>2 \mathrm{yrs}$ & 1 & & 1 & \\
\hline
\end{tabular}

Hosmer and Lemeshow test $(0.116)<0.05, * *$ Significant value, $95 \% \mathrm{CI}=95 \%$ Confidence Interval

Table 6 depicts that all significant variables in bivariate analysis were put into binary regression model. Iron regularity $(\mathrm{AOR}=18.380 ., 95 \% \mathrm{CI}=3.687-91.624, \mathrm{p}=0.005)$ was significantly associated with anemia among pregnant women.

Family member, fruit per week, meat per week, ANC visit, Drinking Tea, Inter pregnancy difference were not significantly associated with anemia. Therefore these variables are not considered as the determinants of anemia. 


\section{DISCUSSION}

The occurrence and etiology of anemia during pregnancy are well known ${ }^{1}$ The results of this study provide more evidence of the influence of well-established underlying factors among all population groups and more so among those who are pregnant. The present study showed that prevalence of anemia was $22.1 \%$. The finding of this study is consistent with study conducted in Ethiopia showed that $21.3 \%$ of pregnant women were anemic. ${ }^{12,13,14,15,16}$ The finding of this study is inconsistent with other study which is done in Western Nepal, Morang District and Eastern Nepal were 41.0 percent, $47.24 \%$ and $46.6 \%$ respectively prevalence of anemia among pregnant women. ${ }^{17,18}$ Finding is also inconsistent with the national data showed that the prevalence of anemia among pregnant were $46 \% .{ }^{10}$ It might be due to this study conducted in only one setting, with small sample size and study done in tertiary level hospital.

Based on the finding of the study showed that pregnant women who came from more than five family members were significantly association with anemia $(\mathrm{OR}=1.872,95 \% \mathrm{CI}=1.032-3.395$, $p=0.037)$. This finding is consistent with a study done on Ethiopia which showed that the family size of five or more was found to be significantly associated with the occurrence of anemia in pregnancy $\quad(\mathrm{OR}=7.74,95 \% \mathrm{CI}=4.15-16.47) .{ }^{19}$ Similarly, a study done in Northwest, Ethopia showed that pregnant mothers who had been living within a family of more than four members were 3.79 times more likely to anemia $(\mathrm{OR}=3.79$, $95 \% \mathrm{CI}=1.56-9.17){ }^{20}$

Knowledge is the springboard for action. The result of the study showed that knowledge about anemia were not significantly associated with anemia $(\mathrm{OR}=1.535,95 \% \mathrm{CI}=0.866-2.722, p=0.141)$. This finding is similar a study conducted in TUTH, Kathmandu showed that majority of the mothers who delivered at Tribhuvan University Teaching hospital had not adequate knowledge for the preventive measure of anemia ${ }^{15}$. In contrast to this study a study conducted at Karnataka showed that significant association between knowledge regarding causes, sign and symptoms of anemia, knowledge regarding proper diet to prevent anemia and status of anemia. ${ }^{21}$ Similarly finding contrast to the study done in India reveals overall $76.5 \%$ of the participants had good knowledge regarding anemia and it association to anemia status. $^{22}$

The finding of this study revealed that the inter pregnancy difference was significantly association with anemia $(\mathrm{OR}=2.732,95 \% \mathrm{CI}=1.3355 .591$, $p=0.005)$. This finding is consistent to the study done in Oromia Region, Ethiopia showed that birth interval below two years were significantly associated with occurrence of anemia in pregnancy $\quad(\mathrm{OR}=1.648,95 \% \mathrm{CI}=1.01-2.694) .{ }^{23}$ Similarly the study done in Rural Area of West Bengal showed birth spacing is an important predictor of anemia. ${ }^{12}$

The finding shows prevalence of anemia higher in $25.1 \%$ multigravida and higher in third trimester $23.9 \%$. Consistent to this result a study done in Eastern Nepal shows that the prevalence of anemia was higher in pregnant women at the second trimester $51.1 \%$ 17. Similarly study done in TUTH shows that the prevalence of anemia was higher in pregnant women at the second trimester $(51.1 \%) .{ }^{15}$ Similarly A study done in Oromia Region, Ethiopia, Study showed that reproductive history of the women like gestational ages being in the third trimester, parity of more than four children, birth interval below two years and history of abortion were significantly associated with occurrence of anemia in pregnancy. ${ }^{16}$

The pregnant women who attained less than or equal to 2 times of ANC visit were 4.1 times more likely to develop anemia than pregnant women who attained more than 2 times of ANC visits $(\mathrm{OR}=4.184,95 \% \mathrm{CI}=1.825-9.590, p=0.000)$. This finding is consistent with the study done in India showed that women who attended to register late in pregnancy were found that highest risk of anemia than early registration. ${ }^{12}$

The finding of the study indicate that pregnant women who were not consume regular iron were 18.38 times more likely to develop anemia than who had consumed iron regularly $(\mathrm{AOR}=18.380$, 
with $95 \% \mathrm{CI}=3.687-91.624, p=0.005)$. This finding is consistent with study showed that hemoglobin status of women who had been on iron supplements had a higher mean hemoglobin or women who were not taking iron supplements had approximately $60 \%$ higher odds of anemia $(p=0.001) .{ }^{24}$ This finding is consistent with study done in India showed that those women who had just started to consume, not consuming were 33.3 percent of anemia than those pregnant women were consume full course. ${ }^{12}$ Consistent to this, a study conducted on Saralahi shows that anaemia reduced from $52.5 \%$ to $2.5 \%$ in one month iron supplementation. The increase in $\mathrm{Hb}$ after iron supplementation was highly significant in women in third trimester than in the women in second trimester $(\mathrm{P}<0.01) .{ }^{25}$ The result of this study contrast to a study done in Gondar, Northwest Ethiopia were showed that supplementation of iron sulphate, folic acid, and multivitamin during the current pregnancy period were not significantly reduce the prevalence of anemia. ${ }^{20}$

The respondents who were from meat consumption less than or equal to once per week were 2.06 times more likely to develop anemia than those who were habit of more than one per week and there is no association between green vegetable and anemia but findings shows that 1.5 times more likely to occur anemia in women who had habit of taking less than 2 times a week green vegetable. This finding was consistent with study done in Oromia Region, Ethiopia shows that respondents who eat vegetables and meat less frequently were higher rate of anemia (vegetables $60.3 \%$ vs. $24.6 \%$, and meat $39.8 \%$ vs $16.0 \%$ ) than those who eat these food items more frequently. Consumption of animal products like red meat, organ meat and egg less than once per week, vegetables less than once per day, showed that statistically significant association with anemia in pregnancy. ${ }^{19}$

Concerning dietary habit among pregnant women, findings of present study showed that there is significant association between dietary habits of fruits consumption and anemia. The respondents who were from habit of fruits consumption less than or equal to two times per week were 3.7 times more likely to develop anemia than those who were habit of more than two per week $(\mathrm{OR}=3.794,95 \% \mathrm{CI}=2.0756 .937$, $\mathrm{p}=0.000$ ). Similar finding present in a study done at Oromia Region, Ethiopia, showed that the study participants who had habit of less frequent consumption of fruits to be significantly associated with the presence of anemia. ${ }^{19}$ Regarding tea habits, finding of this study revealed that there is significantly association between consuming tea immediately after meal or with meal were associated with anemia (OR=8.303, 95\% CI=1.935-35.638, $p=0.001)$. This finding supported the study done at Oromia Region, Ethiopia, taking tea immediately after meal were significantly associated with the presence of anemia. ${ }^{19}$ This finding was supported by study done in Ethiopia showed that $15.3 \%$ were anemia who had taken tea/coffee after meal. ${ }^{20}$

\section{CONCLUSIONS}

Based on the finding of study it could be concluded that anemia is a public health problem of pregnant women and it significantly associated with regularity of iron intake in pregnancy. However, irregularity of iron supplementation was the key determinants for anemia in pregnancy. Findings indicate to emphasize that the raise awareness on regular intake of iron during pregnancy is important. This study does not cover parasitic infestation by testing stool which was limitation of this study.

\section{ACKNOWLEDGEMENTS}

The Researcher are grateful to Associate Professor Jamuna Adhikari who supervised this work and researcher thank Tribhuwan University Teaching Hospital, Kathmandu for allowing us to collect data from respondents for this study. Researcher are also thankful to all the respondents without whom couldn't success. Researcher also thankful for the support of the entire teachers colleagues and library staff for their support and cooperation during literature review.

Conflict of Interests: The researcher declare that they have no conflicts of interest in relation to this study. 
REFERENCES

1. Bothwell TH. Iron requirements in pregnancy and strategies to meet them. The American journal of clinical nutrition. 2000 Jul 1;72(1):257s-64s.

2. Okube OT, Mirie W, Odhiambo E, Sabina W, Habtu M. Prevalence and factors associated with anaemia among pregnant women attending antenatal clinic in the second and third trimesters at pumwani maternity hospital, Kenya. Open J Obstet and Gynecol. 2016 Jan 11;6(01):16.

3. Salhan S, Tripathi V, Singh R, Gaikwad HS. Evaluation of hematological parameters in partial exchange and packed cell transfusion in treatment of severe anemia in pregnancy. Anemia. 2012;2012:7

4. Maskey M, Jha N, Poudel SI, YadavD. Anemia in pregnancy and its associated factors: A study from Eastern Nepal. Nepal J Epidemiol. 2014; 4(4):386-92.

5. Balarajan Y, Ramakrishnan U, Özaltin E, Shankar AH, Subramanian SV. Anaemia in low-income and middle-income countries. The Lancet. 2012 ;378:2123-35.

6. Mbule MA, Byaruhanga YB, Kabahenda M, Lubowa A, Mbule M. Determinants of anaemia among pregnant women in rural Uganda. Rural Remote Health. 2013;13:1549.

7. Siteti MC, Namasaka SD, Ariya OP, Injete SD, Wanyonyi WA. Anaemia in pregnancy: Prevalence and possible risk factors in Kakamega County. Kenya Sci J Pub Health. 2014; 2(3):216-2.

8. Ghosh S, Trevino JA, Davis D, et. al. Factors associated with anemia in pregnant women in Banke, Nepal. The FASEB J. 2017; 31(1S):788-32.

9. Addis Alene K, Mohamed Dohe A. Prevalence of anemia and associated factors among pregnant women in an urban area of eastern Ethiopia. Anemia. 2014 25; 2014.

10. Ministry of Health and Population (MOHP) Nepal, New ERA \& ICF International. . Nepal Demographic and Health Survey. Kathmandu, Nepal: Ministry of Health and Population, New ERA, and ICF International, Calverton, Maryyland. 2011
11. Makhoul Z. Anemia and iron deficiency in rural Nepali pregnant women: Risk factors, effect of vitamin A supplementation and their association with birth outcomes. Available from arizona.openrepository.com

12. Bisoi S, Haldar D, Majumdar $\mathrm{T} K$, Bhattacharya N, Sarkar G N, Ray S K. Correlates of anemia among pregnant women in a rural area of West Bengal. J Fam Welf. 2011; 57(1):72-8.

13. Rebecca J, Stoltzfus L, Mullany, Robert E B. Iron deficiency anemia, Comparative quantification of health risks,2001, p 3- 48

14. World Health Organization (WHO) Haemoglobin concentrations for the diagnosis of anaemia and assessment of severity. Vitamin and Mineral Nutrition Information System.

15. Ghimire N, Pandey N. Knowledge and practice of mothers regarding the prevention of anemia during pregnancy, in teaching hospital, Kathmandu. Journal of Chitwan Medical College. 2013; 3(5): 14-7.

16. Abriha A, Yesuf M E, Wassie M M Prevalence and associated factors of anemia among pregnant women of Mekelle town, A cross sectional study. BMC Res Notes. 2014; 7:888.

17. Singh $\mathrm{P}$, Khan S, Mitta, R K Anemia during pregnancy in the women of Western Nepal. Bali Medical Journal. 2013; 2 (1), 14-6.

18. Sinha A K, Karki G M, Yadav S, Islam M N. Prevalence of anemia during pregnancy in the women of Eastern Nepal. International Journal of Pharmaceutical \& Biological Archives. 2012; 3(5):1051-3.

19. Obse N, Mossie A, Gobena T. Magnitude of anemia and associated risk factors among pregnant women attending antenatal care in Shalla Woreda, West Arsi Zone, Oromia Region, Ethiopia. Ethiop J Health Sci. 2013; 23(2), 165-73.

20. Melku M, Addis Z, Alem M, Enawgaw B. Prevalence and predictors of maternal anemia during pregnancy in Gondar, Northwest Ethiopia: An institutional based cross-sectional study. Anemia. 2014; 9:1-11.

21. Yadav R. K, Swamy M K, Banjade B. Knowledge and practice of anemia among pregnant women attending antenatal clinic 
in Dr. Prabhakar Kore hospital, Karnataka-A cross sectional study. J Dent Med Sci. 2014; 13(4): 74-80.

22. Balasubramanian T, Aravazhi M, Sampath $\mathrm{S}$ D. Awareness of anemia among pregnant women and impact of demographic factors on their hemoglobin status. Int J Scientif Stud. 2016; 3(12), 303-5.

23. Salih S, Alqahtani H, Almaki A, Alfaifi F, Gazwani M, Faqehi H. Anemia and dietary habits among pregnant women in Jazan,
Saudi Arabia. British J Med \& Med Res. 2015; 10(9):1-8.

24. Ononge S, Campbell O, Mirembe F. Haemoglobin status and predictors of anaemia among pregnant women in Mpigi, Uganda. BMC Res Notes. 2014; 7(1), 712.

25. Shah H, Sherchand, J B. Iron supplementation for controlling anemia in pregnancy by involving FCHVs in Saralahi, 2000. 